\title{
Time-Series Modeling and Prediction of Global Monthly Absolute Temperature for Environmental Decision Making
}

\author{
YE Liming ${ }^{1,2}$ (叶立明), YANG Guixia ${ }^{1}$ (杨桂霞), Eric VAN RANST ${ }^{2}$, and TANG Huajun*3 (唐华俊) \\ ${ }^{1}$ Key Laboratory of Agri-Informatics, Ministry of Agriculture/Institute of \\ Agricultural Resources and Regional Planning, \\ Chinese Academy of Agricultural Sciences, Beijing 100081 \\ ${ }^{2}$ Department of Geology and Soil Science (WE13), Ghent University, \\ Krijgslaan 281, 9000 Gent, Belgium \\ ${ }^{3}$ Chinese Academy of Agricultural Sciences, Beijing 100081
}

(Received 4 December 2011; revised 3 June 2012)

\begin{abstract}
A generalized, structural, time series modeling framework was developed to analyze the monthly records of absolute surface temperature, one of the most important environmental parameters, using a deterministicstochastic combined (DSC) approach. Although the development of the framework was based on the characterization of the variation patterns of a global dataset, the methodology could be applied to any monthly absolute temperature record. Deterministic processes were used to characterize the variation patterns of the global trend and the cyclic oscillations of the temperature signal, involving polynomial functions and the Fourier method, respectively, while stochastic processes were employed to account for any remaining patterns in the temperature signal, involving seasonal autoregressive integrated moving average (SARIMA) models. A prediction of the monthly global surface temperature during the second decade of the 21st century using the DSC model shows that the global temperature will likely continue to rise at twice the average rate of the past 150 years. The evaluation of prediction accuracy shows that DSC models perform systematically well against selected models of other authors, suggesting that DSC models, when coupled with other ecoenvironmental models, can be used as a supplemental tool for short-term ( $\sim 10$-year) environmental planning and decision making.
\end{abstract}

Key words: time series analysis, statistical model, polynomial trend, Fourier method, ARIMA, climate change

Citation: Ye, L. M., G. X. Yang, E. Van Ranst, and H. J. Tang, 2013: Time-series modeling and prediction of global monthly absolute temperature for environmental decision making. Adv. Atmos. Sci., 30(2), 382-396, doi: 10.1007/s00376-012-1252-3.

\section{Introduction}

The air temperature at the Earth's surface is one of the most important environmental factors. Modeling the variations of surface temperature and making dependable forecasts underlie the foundation of sound environmental policies (Romilly, 2005). The temporal changes of the global surface temperature, for exam- ple, have been used as a prominent indicator of global climate change, paving the way for smooth communication among environmental researchers, policy makers, and the general public (IPCC, 2007). In a broader context, temperature affects many other environmental factors in complex ways. Examples of such influences include, but are not limited to (1) the positive feedback between ambient temperature and the global

\footnotetext{
*Corresponding author: TANG Huajun, hjtang@caas.ac.cn

(C) China National Committee for International Association of Meteorology and Atmospheric Sciences (IAMAS), Institute of Atmospheric Physics (IAP) and Science Press and Springer-Verlag Berlin Heidelberg 2013
} 
carbon cycle (Grace, 2004; Chapin III et al., 2009), (2) the role of soil temperature in controlling the rate of soil respiration (Conant et al., 2000; Bond-Lamberty and Thomson, 2010) and soil degradation (Bindraban et al., 2012), and (3) the cause-effect relationships between global warming and decreased biodiversity (Mayhew et al., 2008), increased mortality (Chung et al., 2009), and shifts of crop phenology (Peñuelas et al., 2009) and growing seasons (Steltzer and Post, 2009). Moreover, temperature is a critical input parameter in many eco-environmental models in the fields of crop growth simulation (Verdoodt et al., 2004; Bechini et al., 2006), agro-ecological zoning (Caldiz et al., 2001; Ye et al., 2008), and food security assessment (Ye and Van Ranst, 2002, 2009; Ye et al., 2012), for example. Policy analysis using these ecosystem models is only possible with accurate prediction of future temperatures.

Temperature data are usually given as monthly means in an equally spaced time series. Instrumental records used in computing these mean values globally have only been available for the past $\sim 150$ years (Jones and Moberg, 2003). Many efforts have been made in the statistical modeling of temperature variations using these records (e.g., Hansen et al., 2006; Rahmstorf et al., 2007). Among them, the univariate time-series models have gained relative popularity in recent years, partly due to the complexity of mainstream climate models, which are strongly constrained by the current knowledge of the physical climate system (IPCC, 2001). One subcategory of the univariate models, namely the structural time-series models (e.g., Lee and Sohn, 2007), has become quite popular due to its trend-detecting capability. In general, a structural time-series model comprises a deterministic trend plus random residuals about the trend, where the residuals are assumed to represent natural variability and can be viewed as a realization of an autoregressive integrated moving average (ARIMA) process (Romilly, 2005).

However, almost all of these existing statistical models deal with temperature anomalies. Although the expression of temperatures in climate change research in terms of anomaly values relative to a predefined "normal" period (e.g., 1961-90, as in Jones et al., 1999; or 1901-2000, as in Smith et al., 2008) is well justified, the use of temperature anomalies instead of absolute temperatures in the other areas of environmental research introduces extra complexity in data preparation and result interpretation. In addition, the use of temperature anomalies instead of absolute temperatures is not cost-effective (Dale and English, 1999). Unfortunately, models based on temperature anomalies cannot be directly used to deal with absolute temperatures. One reason is that seasonal- ity is intentionally removed from temperature anomalies. Therefore, a different approach to characterizing the variation patterns of absolute temperatures is needed; however, systematic studies regarding the details of this pattern characterization process are still lacking. The objectives of this study were the following: (1) to present a generalized modeling framework of absolute temperatures based on both deterministic and stochastic time-series techniques; (2) to show the performance advantages of the models obtained here over a batch of other models in both in-sample fitting and out-of-sample prediction; (3) to make a short-term ( $\sim 10$-year) prediction of the monthly global surface temperature; and (4) to evaluate the significance of the results obtained.

\section{Material and methods}

\section{$2.1 \quad$ Data}

Monthly global merged land-air-sea surface temperature data (January 1880-December 2011, Fig. 1a), provided by the National Climate Data Center (NCDC) at the National Oceanic and Atmospheric Administration (NOAA) of the United States, were used in this research. This dataset represents one of the best systematic estimates of the average temperature anomalies of the Earth's surface, taking all land and sea surfaces together, based on historical observations (Smith and Reynolds, 2005). The dataset is regularly updated and is freely available (NCDC, 2012).

The absolute temperature $(T)$ was inversely calculated from the temperature anomaly $(\Delta T)$ and the 20th-century average absolute temperature $(\bar{T})$, using the method stipulated by the NCDC (2012):

$$
T_{m}=\Delta T_{m}+\bar{T}_{m}
$$

where $m$ is the month in a year. Both $\Delta T$ and $\bar{T}$ are given by the dataset.

\subsection{Framework of the modeling approach}

A five-step approach was adopted in this research (Fig. 2). First, the whole dataset was divided into two subsets, namely the training set (January 1880 December 2001) and the calibration set (January 2012-December 2011). The temperature data in the training set were statistically analyzed (a) to determine the presence of and (b) to identify the temporal patterns of any global trend and/or periodic oscillation, employing analytical techniques in both time and frequency domains. Second, the residuals of the temperature signal, after the trend and periodicity had been accounted for, were modeled using a seasonal 

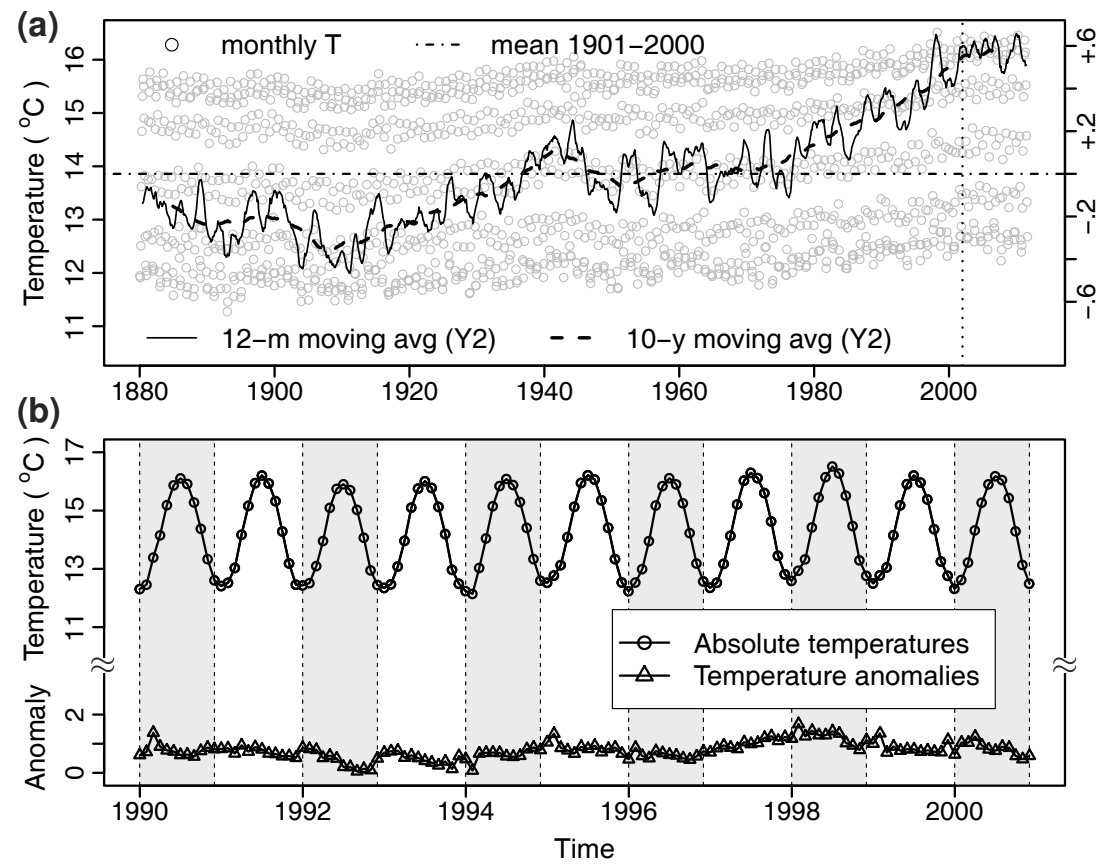

Fig. 1. (a) Time plot of the NCDC monthly global absolute surface temperature series (Smith et al., 2008), January 1880-December 2011 (blank circles) superimposed with two moving-average-smoothed curves using a window length of 12 months (thin solid line) and 120 months (thick dashed line) respectively. The smoothed curves are expressed as temperature anomalies $\left({ }^{\circ} \mathrm{C}\right)$ relative to the 20th-century average (broken horizontal line) and are aligned to the secondary $y$-axis on the right. The dotted vertical line indicates the splitting between the training (January 1880-December 2001) and the calibration (January 2002-December 2011) subsets of the data; (b) time plot of the 1990-2000 section of the NCDC series. The curve of the absolute temperatures (blank circles) exhibits a distinct pattern of recurring oscillations at the annual frequency, while the same pattern is not observed for temperature anomalies (blank triangles). Alternating shaded and unshaded areas mark the boundaries of the annual cycles.

ARIMA process, following the Box-Jenkins approach (Box et al., 1994). Third, the deterministic processes obtained in step one and the stochastic processes obtained in step two were combined to form the candidate models using Eq. (2). The respective adequacies of these candidate models were then vigorously tested. Fourth, the overall performances of the candidate models in both in-sample fitting and out-ofsample prediction were compared to identify the bestperforming model. Finally, a prediction of the global surface temperature in the second decade of the 21st century was made, together with an evaluation of the significance of the predicted warming trend.

The general model used in this research to deal with the time series of absolute temperatures $(T)$ is given by

$$
T=L+C+E,
$$

where $L$ is the trend term, $C$ is the periodicity term or, in other words, the term of cyclic oscillations, and $E$ is the error term. Both $L$ and $C$ can be represented by analytical models and are thus said to be the deterministic components of $T$, while $E$ can be considered as the realization of a seasonal ARIMA process and is thus said to be the stochastic component of $T$.

\subsection{Deterministic processes}

The trend term $L$ in Eq. (2) is defined using

$$
L(j)=a+\sum_{j}\left(b_{j} t^{j}\right),
$$

where $a$ and $b$ are parameters, $t$ is time, and $j$ is the order of the polynomials.

The periodicity term $C$ in Eq. (2) is defined by the Fourier functions as

$$
C(k)=\sum_{k} A_{k} \cos \left(2 \pi f_{k} t+\varphi_{k}\right),
$$




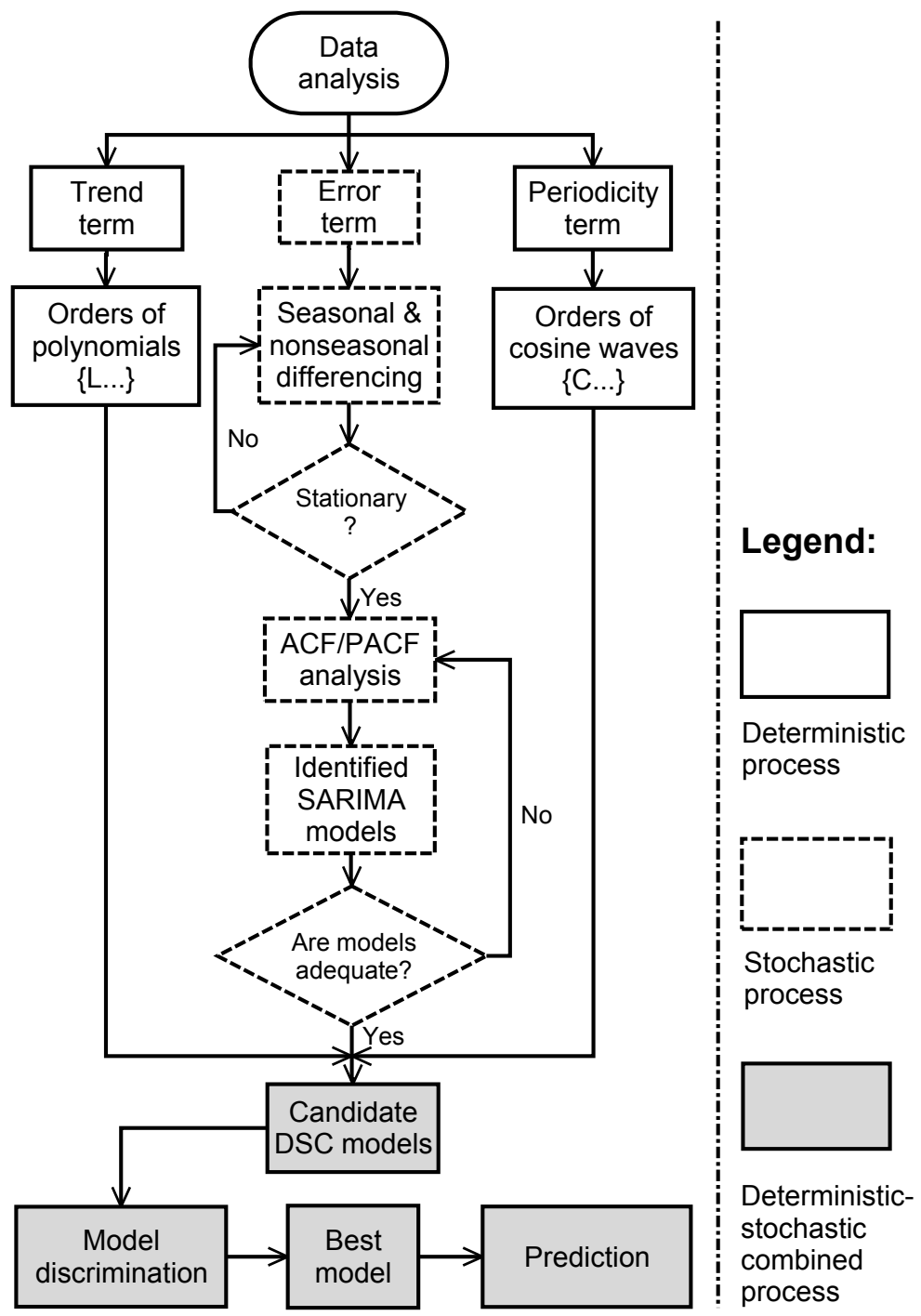

Fig. 2. Functional flowchart of the modeling approach.
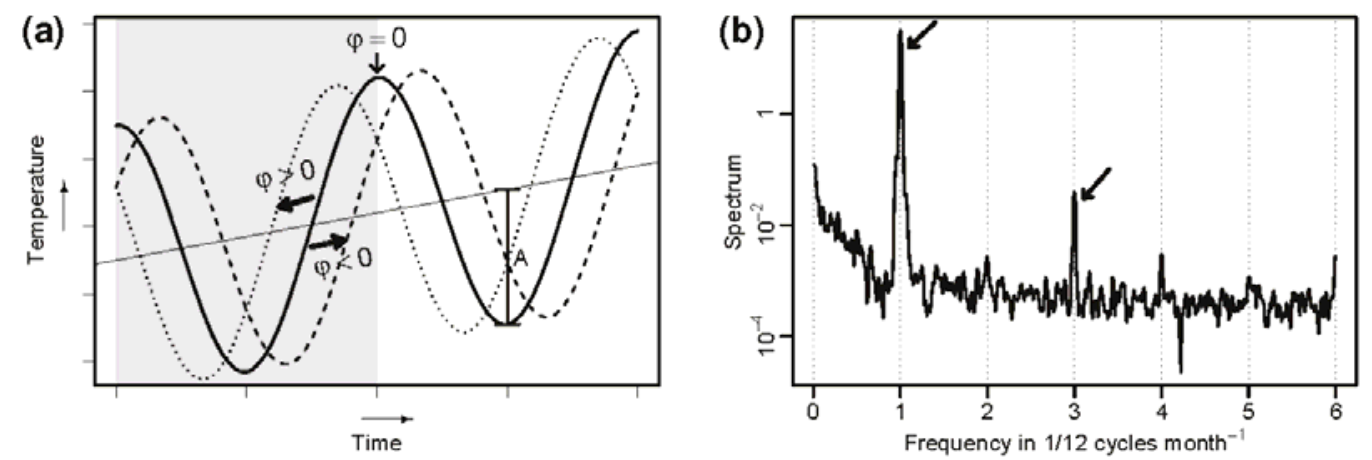

Fig. 3. (a) Theoretical modeling of periodic oscillations of monthly absolute temperatures. The temperature signal is represented by the sum of a linear trend and a stationary sinusoidal wave with amplitude $A$ and phase $\varphi$. The shaded area marks one cycle of the sinusoidal wave; (b) smoothed periodogram (Bloomfield, 2000) of the NCDC absolute temperature data showing a fundamental frequency at $1 / 12$ cycles per month (marked as 1 on the $x$-axis) and its harmonic frequencies at multiples of the fundamental frequency (i.e., $n \times 1 / 12$ cycles per month where $n=2,3,4, \ldots$ as marked on the $x$-axis). 
where $A$ is the amplitude, $\varphi$ is the phase, $f$ is the frequency of the sinusoidal wave in cycles per unit time, and $k$ is the order of the sinusoids, i.e., the number of coexisting sinusoidal waves (Fig. 3a).

\subsection{Stochastic processes}

The following multiplicative seasonal ARIMA model, or seasonal autoregressive integrated moving average (SARIMA) model, of Box and Jenkins (Box et al., 1994) was used to represent the error term $E$ in Eq. (2):

$\Phi_{P}\left(B_{s}\right) \phi(B) \nabla_{D, s} \nabla_{d} E_{t}=\alpha+\Theta_{Q}\left(B_{s}\right) \theta(B) w_{t}$,

where $w_{t}$ is the Gaussian white-noise process; $\phi(B)$ and $\theta(B)$ are the ordinary autoregressive (AR) and moving average (MA) operators of orders $p$ and $q$, respectively; $\Phi_{P}\left(B_{s}\right)$ and $\Theta_{Q}\left(B_{s}\right)$ are the seasonal AR and MA operators of orders $P$ and $Q$, respectively, with seasonal period $s ; B$ is the backshift operator: $B\left(E_{t}\right)=E_{t-1}$ for any value of $E$ at time $t ; B_{s}$ is the seasonal backshift operator: $B_{s}\left(E_{t}\right)=$ $E_{t-s} ; \nabla_{d}$ is the ordinary difference operator, $\nabla_{d}=$ $(1-B)^{d} ; \nabla_{D, s}$ is the seasonal difference operator, $\nabla_{D, s}$ $=\left(1-B_{s}\right)^{D}$; integers $d$ and $D$ are the orders of the ordinary and seasonal differencing, respectively; and $\alpha=\mu\left(1-\phi_{1}-\ldots-\phi_{p}\right)$ with $\mu$ being the mean of $E$. In this model, Eq. (5) is denoted in short as $\operatorname{ARIMA}(p$, $d, q) \times(P, D, Q)_{s}$.

The ordinary AR and MA operators, $\phi(B)$ and $\theta(B)$, in Eq. (5) are given by Eqs. (6) and (7), respectively:

$$
\begin{aligned}
& \phi(B)=1-\sum_{p} \phi_{p} B^{p}, \\
& \theta(B)=1+\sum_{q} \theta_{q} B^{q},
\end{aligned}
$$

where $\phi_{1}, \phi_{2}, \ldots, \phi_{p}$ and $\theta_{1}, \theta_{2}, \ldots, \theta_{q}$ are parameters. The seasonal AR and MA operators, $\Phi_{P}\left(B_{s}\right)$ and $\Theta_{Q}\left(B_{s}\right)$, in Eq. (5) are given by Eqs. (8) and (9), respectively:

$$
\begin{aligned}
& \Phi_{P}\left(B_{s}\right)=1-\sum_{P} \Phi_{P} B^{P s}, \\
& \Theta_{Q}\left(B_{s}\right)=1+\sum_{Q} \Theta_{Q} B^{Q s},
\end{aligned}
$$

where $\Phi_{1}, \Phi_{2}, \ldots, \Phi_{P}$ and $\Theta_{1}, \Theta_{2}, \ldots, \Theta_{Q}$ are parameters.

Thus the general model given in Eq. (2) is said to be a deterministic-stochastic combined (DSC) model of monthly absolute temperatures and can be denoted as $\operatorname{DSC}(j, k)+(p, \mathrm{~d}, q) \times(P, D, Q)_{s}$.

\subsection{Computing techniques}

The open-source statistical package R ( $\mathrm{R}$ Development Core Team, 2008) was used as the computing platform for data analysis, model estimation, model discrimination, and prediction.

\subsubsection{Multiple regressions}

The right-hand side of Eq. (4) is essentially a nonlinear function of the phase variable $\varphi$. Equation (4) can be rewritten in the linear form (Bloomfield, 2000) as

$$
C(k)=\sum_{k}\left(M_{k} \cos 2 \pi f_{k} t+N_{k} \sin 2 \pi f_{k} t\right),
$$

where $M_{k}=A_{k} \cos \varphi_{k}$ and $N_{k}=-A_{k} \sin \varphi_{k}$. In practice, the frequency $f_{k}$ is regarded as known for a particular dataset (Fig. 3b). The values of $M_{k}$ and $N_{k}$ can therefore be statistically determined by solving Eq. (10) using the principle of least squares. Given any values of $M_{k}$ and $N_{k}$, the corresponding values of $A_{k}$ and $\varphi_{k}$ can be obtained using $A_{k}=\sqrt{M_{k}^{2}+N_{k}^{2}}$ and $\varphi_{k}=\arctan \left(-N_{k} / M_{k}\right)$.

Multiple regression analysis was applied to the NCDC temperature data (Fig. 1a) to determine the trend Eq. (3) and periodicity Eq. (10) terms at once:

$\widehat{T}=a+\sum_{j}\left(b_{j} t^{j}\right)+\sum_{k}\left(m_{k} \cos 2 \pi f_{k} t+n_{k} \sin 2 \pi f_{k} t\right)$,

where $\widehat{T}$ is the temperature estimate, and $a, b, m$, and $n$ are parameters. The orders of the polynomial trend and the periodicities, $j$ and $k$, were statistically determined using a "trial and error" approach. For the trend term, if the parameter $b_{j}$ in a model with $j$ polynomials Eq. (11) is significant (i.e., the order $j$ is thus said to be significant, whether parameters $b_{1}, b_{2}, \ldots$, $b_{j-1}$ are significant or not), the model with $(j+1)$ polynomials must also be tried. This looping process stops when two consecutive orders of $j$ are insignificant. Tests (Table 1 ) show that the maximum order of the polynomial trend for the NCDC data is five, where orders six and seven are both insignificant, meaning that the trend term up to the fifth order can be used to construct the candidate models. For the periodicity term, the upper limit of the order $k$ is suggested by data analysis. The spectral analysis (Fig. 3b) of the NCDC data using a smoothed peridogram (Bloomfield, 2000) showed that the temperature signal may contain four sinusoidal waves. Among them, two waves can be easily observed at the fundamental frequency of $1 / 12$ cycles per month and at the harmonic frequency of $1 / 4(=3 \times 1 / 12)$ cycles per month, respectively, as identified by the arrows in Fig. 3b. Other, less obvious waves may also be detected at the frequencies of, for 
Table 1. Deterministic processes Eq. (11) estimated on the NCDC global temperature data. Values in parenthesis are standard errors. The "_" sign means "not applicable", as in the case of parameter $b_{2}$ for models with a linear trend $(j$ $=1$ ). Insignificant parameters (e.g., $\left.b_{4}\right)$ are not listed.

\begin{tabular}{|c|c|c|c|c|c|c|}
\hline \multirow[b]{2}{*}{ Parameter } & \multicolumn{3}{|c|}{$k=1$} & \multicolumn{3}{|c|}{$k=3$} \\
\hline & $j=1$ & $j=2$ & $j=5$ & $j=1$ & $j=2$ & $j=5$ \\
\hline$a$ & $\begin{array}{l}3.6940 \\
(0.2380)\end{array}$ & $\begin{array}{l}2.0740 \times 10^{2} \\
(13.6600)\end{array}$ & $\begin{array}{l}6.0350 \times 10^{5} \\
\left(4.0310 \times 10^{4}\right)\end{array}$ & $\begin{array}{l}3.6888 \\
(0.2278)\end{array}$ & $\begin{array}{l}2.0740 \times 10^{2} \\
(12.9800)\end{array}$ & $\begin{array}{l}6.0340 \times 10^{5} \\
\left(3.7990 \times 10^{4}\right)\end{array}$ \\
\hline$b_{1}$ & $\begin{array}{l}0.0052 \\
(0.0001)\end{array}$ & $\begin{array}{l}-0.2048 \\
(0.0141)\end{array}$ & $\begin{array}{l}-1.1660 \times 10^{3} \\
(77.9200)\end{array}$ & $\begin{array}{l}0.0052 \\
(0.0001)\end{array}$ & $\begin{array}{l}-0.2048 \\
(0.0134)\end{array}$ & $\begin{array}{l}-1.1660 \times 10^{3} \\
(73.4200)\end{array}$ \\
\hline$b_{2}$ & $\begin{array}{l}- \\
-\end{array}$ & $\begin{array}{l}5.4100 \times 10^{-5} \\
\left(3.6270 \times 10^{-6}\right)\end{array}$ & $\begin{array}{l}0.8008 \\
(0.05354)\end{array}$ & $\begin{array}{l}- \\
-\end{array}$ & $\begin{array}{l}5.4100 \times 10^{-5} \\
\left(3.4470 \times 10^{-6}\right)\end{array}$ & $\begin{array}{l}0.8008 \\
(0.0505)\end{array}$ \\
\hline$b_{3}$ & $\begin{array}{l}- \\
-\end{array}$ & $\begin{array}{l}- \\
-\end{array}$ & $\begin{array}{l}-2.0630 \times 10^{-4} \\
\left(1.3790 \times 10^{-5}\right)\end{array}$ & $\begin{array}{l}- \\
-\end{array}$ & $\begin{array}{l}- \\
-\end{array}$ & $\begin{array}{l}-2.0630 \times 10^{-4} \\
\left(1.300 \times 10^{-5}\right)\end{array}$ \\
\hline$b_{5}$ & $\begin{array}{l}- \\
-\end{array}$ & $\begin{array}{l}- \\
-\end{array}$ & $\begin{array}{l}5.4710 \times 10^{-12} \\
\left(3.6610 \times 10^{-13}\right)\end{array}$ & $\begin{array}{l}- \\
-\end{array}$ & $\begin{array}{l}- \\
-\end{array}$ & $\begin{array}{l}5.4710 \times 10^{-12} \\
\left(3.4490 \times 10^{2}\right)\end{array}$ \\
\hline$m_{1}$ & $\begin{array}{l}-0.1249 \\
(0.0061)\end{array}$ & $\begin{array}{l}-0.1249 \\
(0.0057)\end{array}$ & $\begin{array}{l}-0.1249 \\
(0.0053)\end{array}$ & $\begin{array}{l}-0.1249 \\
(0.0058)\end{array}$ & $\begin{array}{l}-0.1249 \\
(0.0054)\end{array}$ & $\begin{array}{l}-0.1249 \\
(0.4994)\end{array}$ \\
\hline$n_{1}$ & $\begin{array}{l}-1.9684 \\
(0.0061)\end{array}$ & $\begin{array}{l}-1.9680 \\
(0.0057)\end{array}$ & $\begin{array}{l}-1.9680 \\
(0.0053)\end{array}$ & $\begin{array}{l}-1.9684 \\
(0.0058)\end{array}$ & $\begin{array}{l}-1.9680 \\
(0.0054)\end{array}$ & $\begin{array}{l}-1.9680 \\
(0.4994)\end{array}$ \\
\hline$m_{3}$ & $\begin{array}{l}- \\
-\end{array}$ & $\begin{array}{l}- \\
-\end{array}$ & $\begin{array}{l}- \\
-\end{array}$ & $\begin{array}{l}0.0129 \\
(0.0058)\end{array}$ & $\begin{array}{l}0.0129 \\
(0.0054)\end{array}$ & $\begin{array}{l}0.0129 \\
(0.4994)\end{array}$ \\
\hline$n_{3}$ & $\begin{array}{l}- \\
-\end{array}$ & $\begin{array}{l}- \\
-\end{array}$ & $\begin{array}{l}- \\
-\end{array}$ & $\begin{array}{l}0.0675 \\
(0.0058)\end{array}$ & $\begin{array}{l}0.0669 \\
(0.0054)\end{array}$ & $\begin{array}{l}0.0669 \\
(0.4994)\end{array}$ \\
\hline
\end{tabular}

example, $1 / 6$ and $1 / 3$ cycles per month, respectively. This suggests that the periodicity term up to the fourth order can be considered in the construction of the candidate models. In total, 20 models $(j=1 \ldots 5$ in combination with $k=1 \cdots 4)$ were attempted; six models $(j=1,2$, and 5 in combination with $k=1$ and 3) tested significant (Table 1 ).

\subsubsection{Seasonal ARIMA}

Seasonal ARIMA models were employed to handle the remaining patterns in the temperature signal that had not been accounted for by the deterministic processes. The time plot of the error term $E$ in Fig. 4a shows no evidence that $E$ is a Gaussian process or that $E$ is stationary, suggesting that hidden patterns are still contained in $E$ and need to be recognized. As a prerequisite, $E$ has to be made stationary before ARIMA modeling can be considered. Both ordinary and seasonal differencing techniques were used to achieve this. The first-order ordinary difference on $E$, or $\nabla E$, produced a nonseasonal stationary state (Fig. 4b) but not a seasonal one (Fig. 4c). The seasonal stationary state was achieved by taking the first-order seasonal difference on $\nabla E$, or $\nabla_{12} \nabla E$. To be more explicit, $E$ was made stationary at the orders of $d=$ $1, D=1$, and $\mathrm{s}=12$ [see Eq. (5)].

The standard deviation $(\sigma)$ of the ordinary and seasonal differences of $E$ was closely monitored to try to avoid over differencing, using the following criteria:

$$
\Delta \sigma_{d}=\sigma\left(\nabla_{d+1} E\right)-\sigma\left(\nabla_{d} E\right)
$$

or

$$
\Delta \sigma_{D}=\sigma\left(\nabla_{D+1,12} \nabla_{d} E\right)-\sigma\left(\nabla_{D, 12} \nabla_{d} E\right),
$$

where $\Delta \sigma_{d}$ is the change of the $\sigma$ value before and after an ordinary difference operation, and $\Delta \sigma_{D}$ is the $\sigma$ value change before and after a seasonal difference operation. Over differencing is detected by an increase in the standard deviation values, or $\Delta \sigma>0$. A $65 \%$ increase in the $\sigma$ value, for example, was observed when the ordinary differencing order was incremented from one $\left[\sigma(\nabla E)=0.11^{\circ} \mathrm{C}\right]$ to two $\left[\sigma\left(\nabla_{2} E\right)=0.18^{\circ} \mathrm{C}\right]$, suggesting that $E$ was over differenced at $d=2$. Similarly, a $73 \%$ increase in the $\sigma$ value, from $0.15^{\circ} \mathrm{C}$ for $\nabla_{1,12} \nabla E$ to $0.26^{\circ} \mathrm{C}$ for $\nabla_{2,12} \nabla E$, occurred when the seasonal difference order was incremented from one to two, showing that $\nabla E$ was over differenced at $D=2$. Moreover, the $\sigma$ values of both $\nabla_{2} E$ and $\nabla_{2,12} \nabla E$ were larger than the baseline level of $\sigma(E)$, contrasting the fact that both $\sigma(\nabla E)$ and $\sigma\left(\nabla_{1,12} \nabla E\right)$ were smaller than the baseline level. This additional evidence suggests that the second-order ordinary or seasonal difference does not tend to create a stationary status, but rather tends to create an $E$ or $\nabla E$ that is not stationary, respectively. 

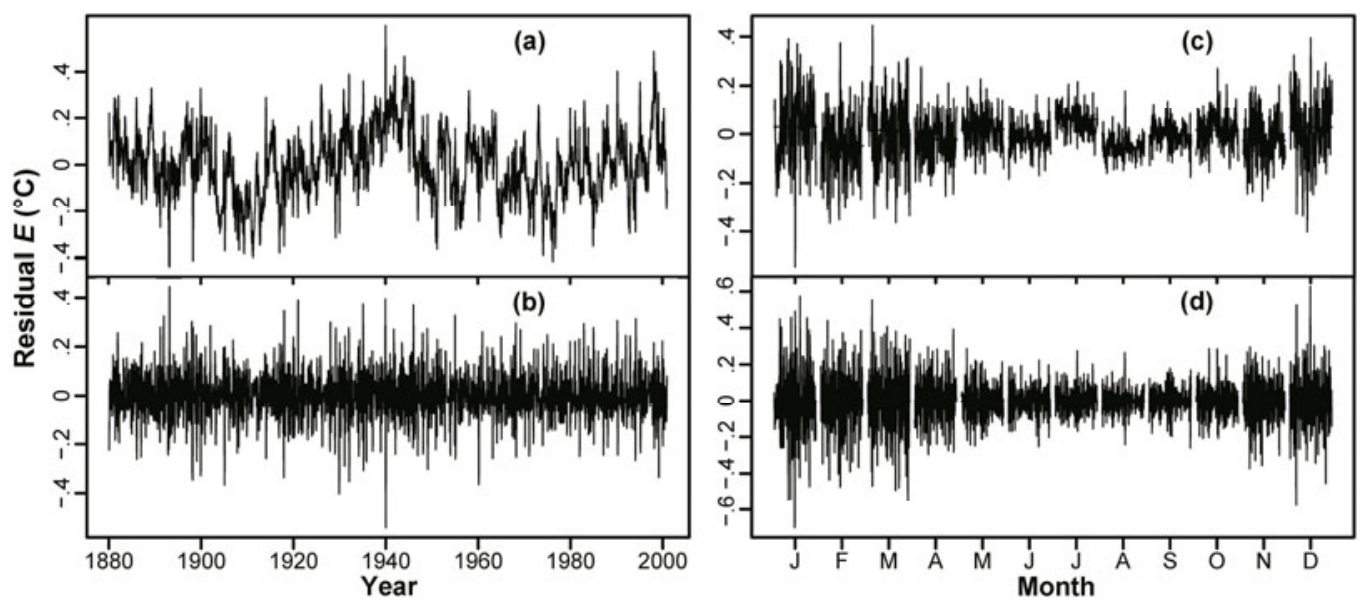

Fig. 4. (a) Time plot of the residual series $E$ in Eq. (2) with both the trend and the periodicity terms being of the second order; (b) time plot of the first-order ordinary difference of series $E$; (c) plot of the monthly subseries, or month plot, of the first-order ordinary difference of series $E$; (d) month plot of the first-order seasonal difference of the first-order ordinary difference of series $E$.
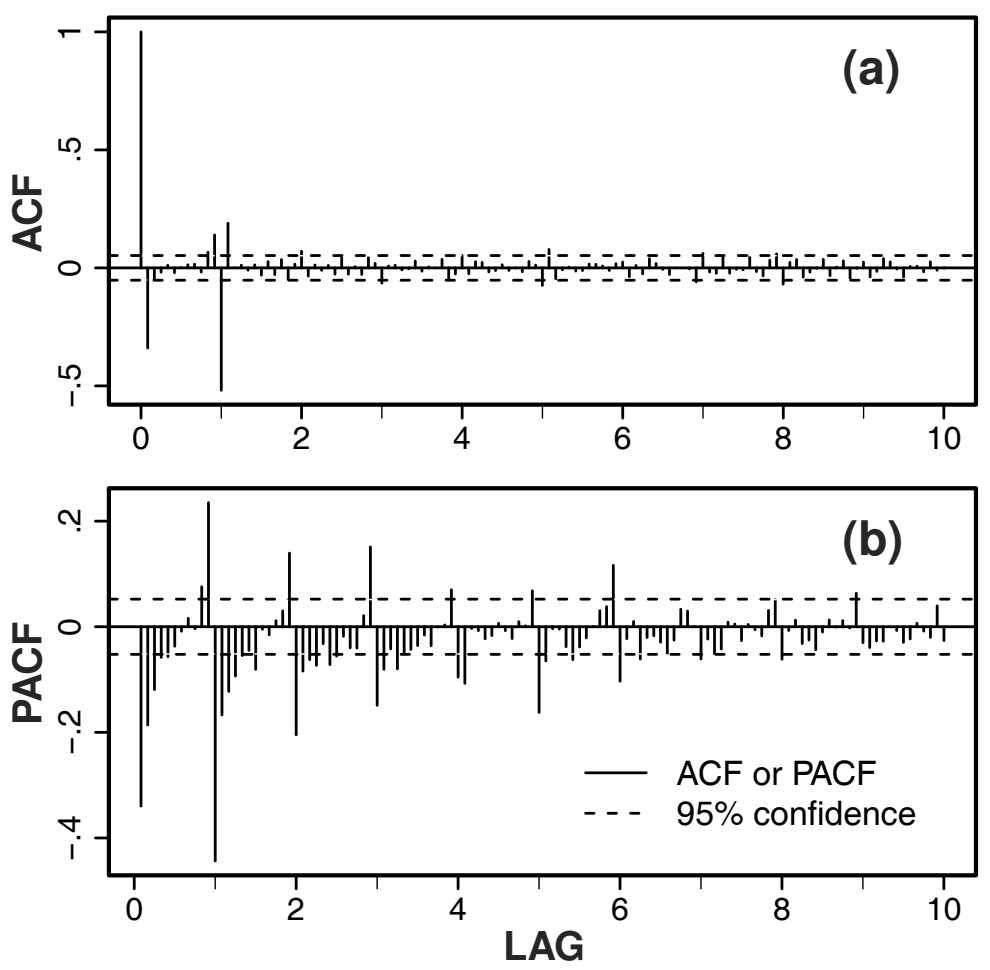

Fig. 5. (a) Sample autocorrelation function $(\mathrm{ACF})$ and (b) sample partial autocorrelation function (PACF) (Venables and Ripley, 2002) of the stationarized residual series $E$ [see Eq. (2) and Fig. 2]. The stationary state was achieved by consecutively taking the first-order ordinary difference and the first-order seasonal difference on series E. Dashed horizontal lines indicate the $95 \%$ confidence interval within which the $\mathrm{ACF}$ or PACF values are not significantly different from zero. The lags are given in the number of years on the $x$-axis. 
Table 2. Creation and numbering of the candidate $\operatorname{DSC}(j$, $k)+(p, d, q) \times(P, D, Q)_{s}$ models based on the characterization of the deterministic and stochastic processes.

\begin{tabular}{ccc}
\hline Orders & \multicolumn{2}{c}{$\operatorname{SARIMA}(p, d, q) \times(P, D, Q)_{s}$} \\
\cline { 2 - 3 }$j$ and $k$ & $(1,1,1) \times(0,1,1)_{12}$ & $(3,1,1) \times(0,1,1)_{12}$ \\
\hline$k=1$ & & \\
$j=1$ & 1 & 2 \\
$j=2$ & 3 & 4 \\
$j=5$ & 5 & 6 \\
$k=3$ & & \\
$j=1$ & & 8 \\
$j=2$ & 7 & 10 \\
$j=5$ & 9 & 12 \\
\hline
\end{tabular}

The sample autocorrelation function (ACF) and the partial sample autocorrelation function (PACF) of $\nabla_{2,12} \nabla E$ were computed (Venables and Ripley, 2002), plotted (Fig. 5), and inspected to identify possible SARIMA models, using the Box-Jenkins diagnostic techniques (Shumway and Stoffer, 2006). Consequently, two nonseasonal and one seasonal component models were identified, resulting in two candidate
SARIMA models, namely $\operatorname{SARIMA}(1,1,1) \times(0,1,1)_{12}$ and $\operatorname{SARIMA}(3,1,1) \times(0,1,1)_{12}$.

\section{Results and discussion}

\subsection{Model estimation}

The DSC models built from the characterized deterministic and stochastic processes are given in Table 2. The parameters of the stochastic processes of the estimated DSC models are given in Table 3, in addition to the parameters of the deterministic processes in Table 1. A comparison between the values and the standard errors of the parameters of both the deterministic and the stochastic processes shows that all of the parameters are, in any case, significantly different from zero. In the worst case, for example, the parameter $m_{3}=0.0129$ (Table $1, j=1, k=3$ ) lies more than two standard errors away from the value $m_{3}=$ 0 , meaning that the third-order periodicity term (i.e., $k=3$ ) can be included into the model at a significance level of $p<0.05$. In fact, the significance levels of the parameters in Tables 1 and 3 are mostly (83 of 86 cases) at $p<0.001$. This is a clear indication of the

Table 3. SARIMA processes of the $\operatorname{DSC}(j, k)+(p, d, q) \times(P, D, Q)_{s}$ models estimated on the NCDC temperature data. The deterministic processes of the same DSC models are given in Table 1. Values in parenthesis are standard errors. The "-" sign means "not applicable", as in the case of parameter $\phi_{2}$ for models with an AR(1) component.

\begin{tabular}{|c|c|c|c|c|c|}
\hline \multirow[b]{2}{*}{ Model } & \multicolumn{3}{|c|}{$\mathrm{AR}$} & \multirow{2}{*}{$\frac{\mathrm{MA}}{\theta}$} & \multirow{2}{*}{$\frac{\text { SMA }}{\Theta}$} \\
\hline & $\phi_{1}$ & $\phi_{2}$ & $\phi_{3}$ & & \\
\hline \multirow[t]{2}{*}{1} & 0.2391 & - & - & -0.7053 & -0.9500 \\
\hline & $(0.0542)$ & - & - & $(0.0421)$ & $(0.0118)$ \\
\hline \multirow[t]{2}{*}{2} & 0.4878 & 0.1665 & 0.0991 & -0.9761 & -0.9472 \\
\hline & $(0.2699)$ & $(0.0295)$ & $(0.0273)$ & $(0.0095)$ & $(0.0129)$ \\
\hline \multirow[t]{2}{*}{3} & 0.2394 & - & - & -0.7056 & -0.9502 \\
\hline & $(0.0542)$ & - & - & $(0.0421)$ & $(0.0118)$ \\
\hline \multirow[t]{2}{*}{4} & 0.4894 & 0.1674 & 0.1003 & -0.9785 & -0.9484 \\
\hline & $(0.0277)$ & $(0.0295)$ & $(0.0273)$ & $(0.0091)$ & $(0.0130)$ \\
\hline \multirow[t]{2}{*}{5} & 0.2396 & - & - & -0.7059 & -0.9503 \\
\hline & $(0.0542)$ & - & - & $(0.0408)$ & $(0.0118)$ \\
\hline \multirow[t]{2}{*}{6} & 0.5043 & 0.1777 & 0.1133 & -1.0000 & -0.9453 \\
\hline & $(0.0261)$ & $(0.0290)$ & $(0.0262)$ & $(0.0034)$ & $(0.0132)$ \\
\hline \multirow[t]{2}{*}{7} & 0.2391 & - & - & -0.7053 & -0.9500 \\
\hline & $(0.0542)$ & - & - & $(0.0408)$ & $(0.0118)$ \\
\hline \multirow[t]{2}{*}{8} & 0.4878 & 0.1665 & 0.0991 & -0.9761 & -0.9472 \\
\hline & $(0.0278)$ & $(0.0295)$ & $(0.0273)$ & $(0.0095)$ & $(0.0129)$ \\
\hline \multirow[t]{2}{*}{9} & 0.2394 & - & - & -0.7056 & -0.9502 \\
\hline & $(0.0542)$ & - & - & $(0.0421)$ & $(0.0118)$ \\
\hline \multirow[t]{2}{*}{10} & 0.4289 & 0.1674 & 0.1003 & -0.9785 & -0.9484 \\
\hline & $(0.0277)$ & $(0.0295)$ & $(0.0273)$ & $(0.0091)$ & $(0.0130)$ \\
\hline \multirow[t]{2}{*}{11} & 0.2396 & - & - & -0.7059 & -0.9503 \\
\hline & $(0.0542)$ & - & - & $(0.0422)$ & $(0.0118)$ \\
\hline \multirow[t]{2}{*}{12} & 0.5043 & 0.1777 & 0.1133 & -1.0000 & -0.9453 \\
\hline & $(0.0261)$ & $(0.0290)$ & $(0.0262)$ & $(0.0034)$ & $(0.0132)$ \\
\hline
\end{tabular}



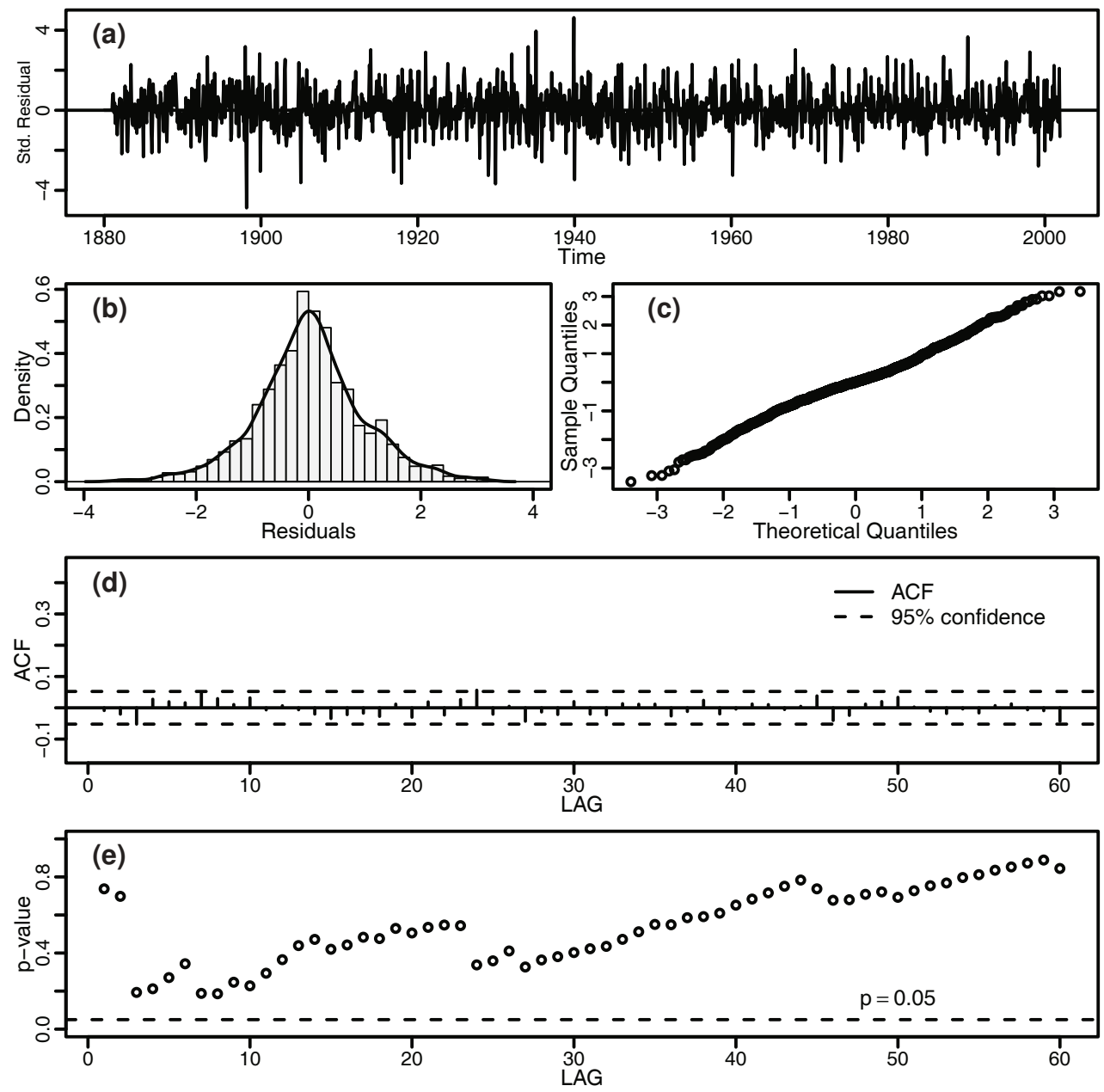

Fig. 6. Statistical diagnostics of the adequacy of DSC model \#2 (see Table 2). (a) Time plot of the standardized residual series $e^{\prime}=e / \sigma(e)$, where $e$ is the residual series of model $\# 2$ and $\sigma(e)$ is the standard deviation of $e$; (b) histogram of $e^{\prime}$ superposed with the density curve of $e^{\prime}$; (c) normal-QQ plot of $e^{\prime}$; (d) sample autocorrelation function (ACF) of $e$; (e) the Ljung-Box goodness-of-fit test of $e$. The lags in both (d) and (e) are given in months on the $x$-axis.

validity of the characterization of the orders of the DSC models.

\subsection{Model adequacy}

The residual series of each of the estimated DSC models (Table 2) was statistically analyzed to ensure model adequacy. The analyses of the adequacy of DSC model \#2 are shown in Fig. 6 as an example. A visual check of the time plot of the standardized residual series $\left(e^{\prime}\right)$ of DSC model \#2 (Fig. 6a) shows that the time plot is analogous to that of a typical, random noise process, primarily suggesting that no sensible patterns are still contained in $e^{\prime}$. The histogram of the standardized residual series (Fig. 6b) reveals that the residual series is normally distributed. The normality of the residual series is further confirmed by the linearity be- tween the quantiles of $e^{\prime}$ and the quantiles of a theoretically normally distributed process (Fig. 6c). The sample autocorrelation function $(\mathrm{ACF})$ of the residual series (e) of DSC model \#2 (Fig. 6d) shows that no spikes of the ACF are extended beyond the boundaries of the $95 \%$ confidence interval, meaning that the values of the $\mathrm{ACF}$ are not significantly different from zero at the lags ranging from $h=0$ to, for example, $h=60$ months. This suggests that $e$ is not autocorrelated. The results of the Ljung-Box goodness-offit test (Ljung and Box, 1978) of $e$ (Fig. 6e) reveals that all of the obtained $p$-values are larger than the significance threshold of $p=0.05$. These relatively large $p$-values confirm that the variation patterns of the temperature signal in the NCDC dataset have been adequately accounted for and that the remaining residuals 
Table 4. In-sample fitting and out-of-sample forecasting performances of the $\operatorname{DSC}(j, k)+(p, d, q) \times(P, D, Q)_{s}$ models estimated on the NCDC temperature data. Models are ranked by criterion, with the ranking values given in parentheses. Rank 1 represents the highest performance. The categorical rank is calculated based on the sum of the ranking values per category (e.g., $\bar{R}^{2}+$ AIC + SIC for "fit").

\begin{tabular}{|c|c|c|c|c|c|c|c|c|c|c|}
\hline \multirow[b]{2}{*}{ Model } & \multicolumn{3}{|c|}{ Fit } & \multicolumn{4}{|c|}{ Forecast } & \multicolumn{3}{|c|}{ Rank } \\
\hline & $\bar{R}^{2}$ & AIC & $\mathrm{BIC}$ & $\bar{R}^{2}$ & RMSE & MAE & MAPE & Fit & Forecast & Overall \\
\hline 1 & $\begin{array}{l}0.9956 \\
(3)\end{array}$ & $\begin{array}{l}-3.7084 \\
(7)\end{array}$ & $\begin{array}{l}-4.6831 \\
(5)\end{array}$ & $\begin{array}{l}0.9931 \\
(3)\end{array}$ & $\begin{array}{l}0.1237 \\
(5)\end{array}$ & $\begin{array}{l}0.0970 \\
(5)\end{array}$ & $\begin{array}{l}0.6979 \\
(5)\end{array}$ & 6 & 5 & 5 \\
\hline 2 & $\begin{array}{l}0.9956 \\
(3)\end{array}$ & $\begin{array}{l}-3.7257 \\
(3)\end{array}$ & $\begin{array}{l}-4.6931 \\
\text { (1) }\end{array}$ & $\begin{array}{l}0.9936 \\
(1)\end{array}$ & $\begin{array}{l}0.1112 \\
(1)\end{array}$ & $\begin{array}{l}0.0883 \\
(1)\end{array}$ & $\begin{array}{l}0.6353 \\
(1)\end{array}$ & 2 & 1 & 1 \\
\hline 3 & $\begin{array}{l}0.9956 \\
(3)\end{array}$ & $\begin{array}{l}-3.7071 \\
(8)\end{array}$ & $\begin{array}{l}-4.6782 \\
(7)\end{array}$ & $\begin{array}{l}0.9926 \\
(7)\end{array}$ & $\begin{array}{l}0.1325 \\
(7)\end{array}$ & $\begin{array}{l}0.1039 \\
(8)\end{array}$ & $\begin{array}{l}0.7455 \\
(7)\end{array}$ & 8 & 8 & 8 \\
\hline 4 & $\begin{array}{l}0.9956 \\
(3)\end{array}$ & $\begin{array}{l}-3.7248 \\
(4)\end{array}$ & $\begin{array}{l}-4.6886 \\
(2)\end{array}$ & $\begin{array}{l}0.9931 \\
(3)\end{array}$ & $\begin{array}{l}0.1152 \\
(3)\end{array}$ & $\begin{array}{l}0.0911 \\
(3)\end{array}$ & $\begin{array}{l}0.6553 \\
(1)\end{array}$ & 3 & 3 & 2 \\
\hline 5 & $\begin{array}{l}0.9956 \\
(3)\end{array}$ & $\begin{array}{l}-3.7045 \\
(10)\end{array}$ & $\begin{array}{l}-4.6683 \\
(10)\end{array}$ & $\begin{array}{l}0.9827 \\
(9)\end{array}$ & $\begin{array}{l}0.2667 \\
(9)\end{array}$ & $\begin{array}{l}0.2152 \\
(9)\end{array}$ & $\begin{array}{l}1.5202 \\
(9)\end{array}$ & 10 & 9 & 11 \\
\hline 6 & $\begin{array}{l}0.9957 \\
(1)\end{array}$ & $\begin{array}{l}-3.7289 \\
(1)\end{array}$ & $\begin{array}{l}-4.6855 \\
(3)\end{array}$ & $\begin{array}{l}0.9815 \\
(11)\end{array}$ & $\begin{array}{l}0.3007 \\
(11)\end{array}$ & $\begin{array}{l}0.2478 \\
(11)\end{array}$ & $\begin{array}{l}1.7469 \\
(11)\end{array}$ & 1 & 11 & 6 \\
\hline 7 & $\begin{array}{l}0.9956 \\
(3)\end{array}$ & $\begin{array}{l}-3.7057 \\
(9)\end{array}$ & $\begin{array}{l}-4.6731 \\
(9)\end{array}$ & $\begin{array}{l}0.9931 \\
(3)\end{array}$ & $\begin{array}{l}0.1237 \\
(5)\end{array}$ & $\begin{array}{l}0.0970 \\
(5)\end{array}$ & $\begin{array}{l}0.6979 \\
(6)\end{array}$ & 9 & 6 & 7 \\
\hline 8 & $\begin{array}{l}0.9956 \\
(3)\end{array}$ & $\begin{array}{l}-3.7229 \\
(5)\end{array}$ & $\begin{array}{l}-4.6832 \\
(4)\end{array}$ & $\begin{array}{l}0.9942 \\
(1)\end{array}$ & $\begin{array}{l}0.1112 \\
(1)\end{array}$ & $\begin{array}{l}0.0883 \\
(1)\end{array}$ & $\begin{array}{l}0.6353 \\
(1)\end{array}$ & 5 & 1 & 2 \\
\hline 9 & $\begin{array}{l}0.9956 \\
(3)\end{array}$ & $\begin{array}{l}-3.7043 \\
(11)\end{array}$ & $\begin{array}{l}-4.6682 \\
(11)\end{array}$ & $\begin{array}{l}0.9926 \\
(7)\end{array}$ & $\begin{array}{l}0.1325 \\
(7)\end{array}$ & $\begin{array}{l}0.1038 \\
(7)\end{array}$ & $\begin{array}{l}0.7455 \\
(7)\end{array}$ & 11 & 7 & 10 \\
\hline 10 & $\begin{array}{l}0.9956 \\
(3)\end{array}$ & $\begin{array}{l}-3.7220 \\
(6)\end{array}$ & $\begin{array}{l}-4.6787 \\
(6)\end{array}$ & $\begin{array}{l}0.9931 \\
(3)\end{array}$ & $\begin{array}{l}0.1152 \\
(3)\end{array}$ & $\begin{array}{l}0.0911 \\
(3)\end{array}$ & $\begin{array}{l}0.6553 \\
(1)\end{array}$ & 6 & 3 & 4 \\
\hline 11 & $\begin{array}{l}0.9956 \\
(3)\end{array}$ & $\begin{array}{l}-3.7071 \\
(12)\end{array}$ & $\begin{array}{l}-4.6584 \\
(12)\end{array}$ & $\begin{array}{l}0.9827 \\
(9)\end{array}$ & $\begin{array}{l}0.2699 \\
(10)\end{array}$ & $\begin{array}{l}0.2153 \\
(10)\end{array}$ & $\begin{array}{l}1.5210 \\
(10)\end{array}$ & 12 & 10 & 12 \\
\hline 12 & $\begin{array}{l}0.9957 \\
(1)\end{array}$ & $\begin{array}{l}-3.7261 \\
(2)\end{array}$ & $\begin{array}{l}-4.6756 \\
(8)\end{array}$ & $\begin{array}{l}0.9825 \\
(11)\end{array}$ & $\begin{array}{l}0.3011 \\
(12)\end{array}$ & $\begin{array}{l}0.2482 \\
(12)\end{array}$ & $\begin{array}{l}1.7499 \\
(12)\end{array}$ & 4 & 12 & 8 \\
\hline
\end{tabular}

are nothing but Gaussian noise.

\subsection{Model discrimination}

\subsubsection{Model selection}

The overall performance of each of the candidate DSC models was evaluated on the basis of the measurements of the model's goodness of fit against the training subset of the NCDC data and the model's forecasting accuracy against the calibration subset of the data. The model's in-sample fitting performance was measured using the adjusted coefficient of determination $\left(\bar{R}^{2}\right)$, Akaike's (1974) information criterion (AIC), and the Schwarz (1978) information criterion (SIC), while the model's out-of-sample forecasting accuracy was measured using the root-mean-squared error (RMSE), the mean absolute error (MAE), and the mean absolute percentage error (MAPE), as suggested by De Gooijer and Hyndman (2006), in addition to $\bar{R}^{2}$. The results (Table 4 ) show that all of the models fit the temperature data well. At least $99 \%$ and $98 \%$ of the variations in the training and calibration subsets of the temperature data, respectively, were reproduced by the DSC models. DSC model \#6, which is composed of a quintic trend, a single sinusoidal periodicity, and an error term represented by a SARIMA $(3,1,1) \times(0,1,1)_{12}$ process (Table 2$)$, was determined to be the best model at fitting the training data, while DSC model \#2, whose linear trend (Table 2) was the only difference from DSC model \#6 and DSC model \#8, whose triple sinusoidal periodicity was the only difference from DSC model \#2, were determined to be the best models at making out-of-sample forecasts. Taking both the in-sample fitting and out-of-sample forecasting together, DSC model \#2 was determined to be the model with the highest overall performance (Table 4).

\subsubsection{Model calibration}

The forecasting performance of DSC model \#2 is illustrated in Fig. 7a by comparing the predicted temperatures to the observed temperatures in the calibration subset (January 2002-December 2011) of the NCDC data. The comparison shows that the observed and the predicted temperatures compare well. Statistics (Table 4 ) show that $99.4 \%$ of the variations in the calibration data were reproduced by the model. The RMSE and MAE of this forecast are $0.11^{\circ} \mathrm{C}$ and 

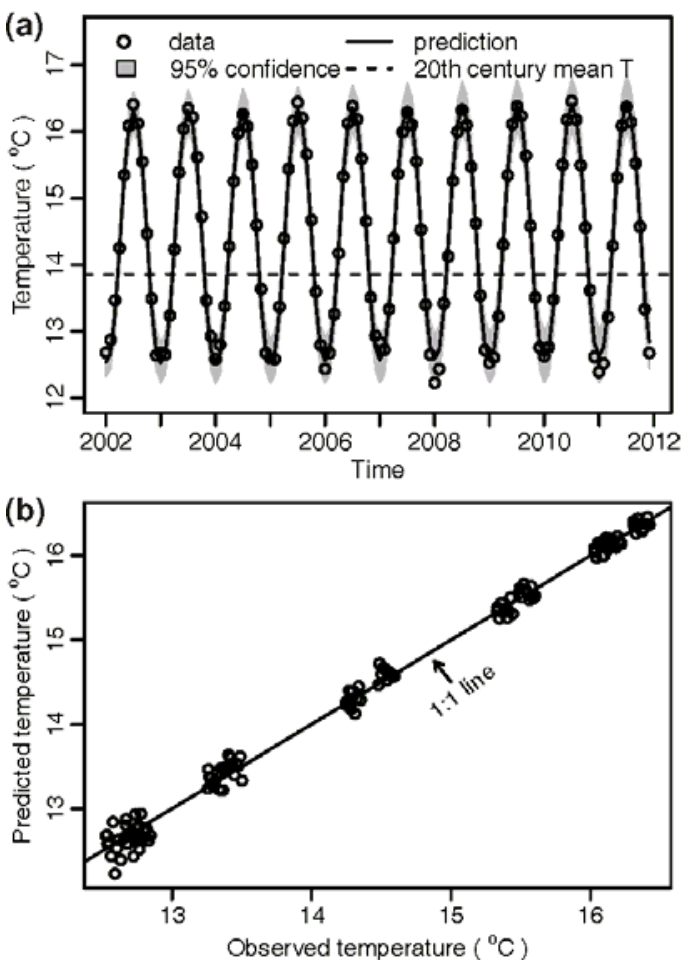

Fig. 7. Comparison between the predicted and the observed temperatures, January 2002-December 2011. The prediction was made with model \#2 (Table 2). (a) Time plot of the predicted (solid line) and the observed (blank circles) temperatures; (b) scatter plot of the predicted and the observed temperatures against the solid 1:1 line.

$0.09^{\circ} \mathrm{C}$, respectively, while the MAPE is merely $0.63 \%$, relative to the average of the predicted temperatures at $14.3^{\circ} \mathrm{C}$. Moreover, the model shows no sign of biased estimations across the entire duration of the prediction period ( $\sim 10$ years), as suggested by the scatter plot of the predicted temperatures and the observed temperatures against the 1:1 line in Fig. $7 \mathrm{~b}$.

\subsection{Forecasting with the best-performing model}

The monthly global surface temperature during the second decade of the 21st century was forecast using DSC model \#2. The global surface temperature was predicted to rise at a steady rate of $0.12^{\circ} \mathrm{C}$ per decade during the prediction period (Fig. 8a). This result suggests that the global temperature will continue to rise during the second decade of the 21st century at a rate consistent with the warming during the "pronounced warming period" of 1970-2000 (Fig. 1a; see Smith and Reynolds, 2005; Hansen et al., 2006). However, the predicted warming is considerably lower not only than IPCC's prediction of $0.2^{\circ} \mathrm{C}$ per decade (IPCC, 2007) but also lower than the prediction made by Lean and Rind (2009) in which anthropogenic influences and natural variability were explicitly considered. Lean and Rind (2009) predicted that anthropogenic influences and solar irradiance will increase the global surface temperature $0.15^{\circ} \mathrm{C}$ in 2014 , compared to 2009. But as a result of declining solar activity, average temperature in 2019 was predicted to be only $0.03^{\circ} \mathrm{C}$ higher than in 2014 . This translates into a $0.72^{\circ} \mathrm{C}$ and $0.76^{\circ} \mathrm{C}$ warming over the 20th-century mean in 2014 and 2019, respectively, compared to our predictions of $0.61^{\circ} \mathrm{C}$ and $0.66^{\circ} \mathrm{C}$, respectively. From a broader perspective, nevertheless, the predicted warming rate is twice the average rate of $0.52^{\circ} \mathrm{C}$ per century (as reflected by the value of parameter $b_{1}$ in Table $1, j$ $=1, k=1$ ) derived from the instrumental records of temperature during the last 150 years, suggesting that the rate of global warming may continue to be unprecedented, despite the current debate over the cause of the stagnated warming observed during the past decade and over future warming (Knight et al., 2009; Kerr, 2009; Wang et al., 2010a, b; see section 3.4.1). As a result, the annual mean temperature in 2017 is expected to bypass that of the warmest year on record, being either 1998 (Jones et al., 1999) or 2005 (Smith et al., 2008; Fig. 8b). This is notable because global temperature reached the record warmth in 2005 without receiving a boost from an El Niño event (Hansen et al., 2006), meaning that global temperature could become higher than predicted if it is coincident with a strong El Niño. The results also show that the global temperature is predicted to rise by $0.6^{\circ} \mathrm{C}-0.7^{\circ} \mathrm{C}$ above the 20th-century mean during the second half of the prediction period (Fig. 8b), with $0.6^{\circ} \mathrm{C}$ being the net warming observed in 2005. A comparison between the magnitude of the predicted warming and the magnitude of the uncertainties associated with the prediction in terms of standard errors during 2017-21 (Fig. 8a, green shading), and in terms of the min-max range and the interquartile range (IQR; Fig. 8b, the height of the whiskers and the height of the box in yellow, respectively), suggests with moderate confidence that the predicted warming is likely unavoidable.

\subsubsection{Uncertainties}

The Monte Carlo approach was employed to examine the uncertainties associated with the modelpredicted warming trend. Box-and-whisker plots of annual global temperature during 2012-21 were produced from 1000 runs of DSC model \#2 (Fig. 8b). The average IQR during the prediction period was measured at $0.20^{\circ} \mathrm{C}$, relative to the predicted average annual temperature of $14.49^{\circ} \mathrm{C}$ during the period or an overall warming of $0.63^{\circ} \mathrm{C}$ above the 20th-century mean. The predicted warming trend of $0.12^{\circ} \mathrm{C}$ per 

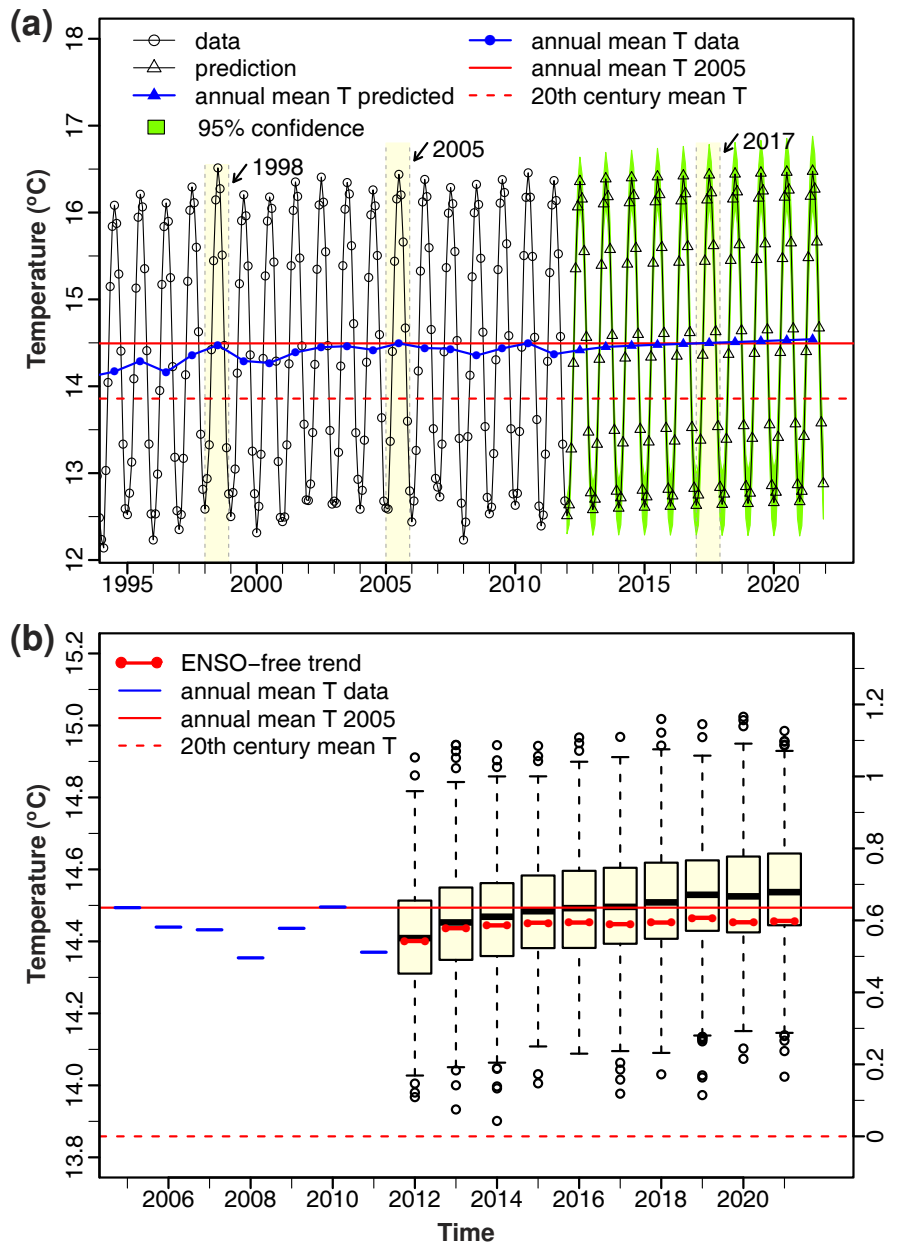

Fig. 8. (a) Monthly global surface temperature as observed (before December 2011, open circles) and predicted (January 2012-December 2021, open triangles). The prediction was made with DSC model \#2 (Table 2). The annual mean global temperature is projected to bypass the 2005-level in 2017, with a net warming of at least $+0.6^{\circ} \mathrm{C}$ relative to the 20th-century mean $\left(13.86^{\circ} \mathrm{C}\right.$, dashed horizontal line); (b) boxand-whisker plots of the DSC model \#2-predicted annual mean global surface temperature during 2012-21, in comparison to the observed annual mean surface temperature during 2005-11 represented by the horizontal bars in blue, showing the predicted warming trend and its associated uncertainties in terms of the min-max range between the top and bottom whiskers and the interquartile range or the height of the box in yellow color.

decade, represented by the upward trend of the thick horizontal bars located in the middle of the boxes in yellow (i.e., the median values, Fig. 8b), depicts one trajectory of temperature change - hopefully the most probable one - within the yellow boxes. The ENSOfree trend, represented by the thick segments of red lines, obtained by subtracting ENSO's warming effect of $0.08^{\circ} \mathrm{C}$ per decade from the predicted trend, is much flatter than the predicted trend but still falls within the IQR represented by the yellow boxes (Fig. 8b). This suggests that trajectories of temperature change, other than the one represented by the median values, are possible although statistically less likely. In other words, the model only provides moderate confidence, and the predicted warming trend should be considered with caution.

Many factors cause climate change. While high anthropogenic gas concentrations (i.e., greenhouse gases and tropospheric aerosols) are major drivers behind warming temperature, the contribution of natural influences (e.g., solar activity in particular) to global temperatures is also remarkable. Recent model-based 
Table 5. Structure of selected models. The "-" sign means "not applicable".

\begin{tabular}{lcccc}
\hline Model & Trend & Periodicity & ARIMA & Source \\
\hline Random Walk & - & - & $(1,1,0) \times(1,1,0) 12$ & Gordon (1991) \\
Pure SARIMA & - & - & $(3,1,1) \times(0,1,1) 12$ & Nickerson and Madsen (2005) \\
Pure analytical & linear & $1 / 12$ cycles per month & - & Madsen et al. (1992) \\
Mixed & linear & - & $(3,1,1) \times(0,1,1) 12$ & Visser and Molenaar (1995) \\
\hline
\end{tabular}

Table 6. Comparison between the forecasting performances of DSC model \#2 against models in Table 5. Models are ranked per criterion, with the ranking values given in parentheses. Rank 1 represents the highest performance. The overall rank is calculated per model based on the sum of the ranking values.

\begin{tabular}{lccccc}
\hline Model & $\bar{R}^{2}$ & RMSE & MAE & MAPE & Rank \\
\hline DSC Model \#2 & $0.9936(3)$ & $0.1112(1)$ & $0.0883(1)$ & $0.6353(1)$ & 1 \\
Random Walk & $0.9171(4)$ & $1.0739(4)$ & $0.9904(4)$ & $6.9334(4)$ & 4 \\
Pure analytical & $0.9948(1)$ & $0.1739(3)$ & $0.1482(3)$ & $1.0427(3)$ & 3 \\
Mixed & $0.9942(2)$ & $0.1403(2)$ & $0.1149(2)$ & $0.8128(2)$ & 2 \\
\hline
\end{tabular}

studies reveal that increasing anthropogenic gas concentrations produced $0.3^{\circ} \mathrm{C}-0.5^{\circ} \mathrm{C}$ warming per century over the 1906-96 period and are the dominant cause of the recent warming since 1976 (Allen et al., 2006). In contrast, natural influences also substantially alter global surface temperatures, producing as much as $0.2^{\circ} \mathrm{C}$ warming during major ENSO events, $\sim 0.3^{\circ} \mathrm{C}$ cooling following large volcanic eruptions, and $0.1^{\circ} \mathrm{C}$ warming from minima to maxima of recent solar cycles (Lean and Rind, 2008). The global surface temperature warmed little from 1999 to 2008 (Fig. 1a; Knight et al., 2009), even as greenhouse gas concentrations have increased. Although the cause of this warming stagnation is being debated, the facts suggest that more attention is needed toward the separation of the effects of natural influences from the effects of anthropogenic gas concentrations on global temperature.

One of the drawbacks of pure empirical models is that such models lack explicit consideration of driving factors behind the problem that is being modeled and are thus inferior in associating predicted changes to relevant causes in the problem domain. Although the predicted warming of $0.12^{\circ} \mathrm{C}$ per decade during 2012-21 is consistent with the recent warming during 1970-2000 and is comparable in magnitude to other forecasts (e.g. Lean and Rind, 2009), it does not reflect the current trend of stagnated warming during the past decade (Fig. 1a; Kerr, 2009). Considering that solar irradiance is expected to increase at the end of its current 11-year cycle, overlapping the first half of the prediction period, and considering that the occurrences of ENSO, primarily with periods of two to four years, and considering that volcanic events are more difficult to predict, the end of the ongoing warming stagnation is predictable, but uncertainty remains regarding the exact timing. Obviously, including anthropogenic and natural parameters into the modeling framework (Fig. 2) is a desirable step toward improved prediction performance.

\subsection{Comparison to other models}

The out-of-sample forecasting performance of DSC model \#2 was compared to that of several other models (Table 5) that were developed to represent the temperature or other environmental parameters such as precipitation. Gorden (1991), for instance, hypothesized that the interannual change of global temperature closely resembles the process of a random walk, i.e., ARIMA without moving average components, while Visser and Molenaar (1995) used linear trends together with ARIMA to detect global warming from Dutch and the Northern Hemispheric temperature data. A pure analytical model consisting of a linear trend and a single sinusoidal wave component, as suggested by Madsen et al. (1992) for analyzing precipitation data from Florida, is also included in Table 6 for performance comparisons.

The modeling results show that DSC model \#2 had the best overall performance in making short-term ( 10-year) predictions of monthly absolute temperatures (Table 6 ). The prediction errors of DSC model \#2 were the least among the models considered, no matter whether these errors were expressed in terms of the root-mean-squared error (RMSE), the mean absolute error (MAE) or the mean absolute percentage error (MAPE). This finding suggests that DSC models can be used to make dependable predictions over the short term. The results also show that the mixed model (Visser and Molenaar, 1995), which differs from the DSC models in that a periodicity term is not pre- 
sented in the former, is the second best performing model in prediction making (Table 5). Although the predictions made by the pure analytical model (Madsen et al., 1992) had the highest goodness of fit, in terms of the adjusted $R^{2}$, against the calibration data, these predictions were not as accurate as those made by the DSC model or the mixed model. It is not a surprise that the random walk model (Gorden, 1991) was systematically inferior to the other models because the month-to-month and year-to-year variations of the surface temperature are driven by many factors (see IPCC, 2007 for "climatic forcing") and because the theory of tossing coins cannot reproduce these variations accurately.

\section{Conclusions}

The proposed DSC models were successfully applied on the NCDC global monthly absolute temperature data. The evaluation of the candidate DSC models (Table 5) revealed that the variations in the NCDC temperature time series can be well characterized by using a linear trend, a single cosine wave at the fundamental frequency of $1 / 12$ cycles per month and a SARIMA $(3,1,1) \times(0,1,1)_{12}$ process. This $\operatorname{DSC}(1,1)+(3,1,1) \times(0,1,1) 12$ model is recognized to have the best overall performance, taking in-sample fitting and out-of-sample forecasting together. The model predicts with moderate confidence that the global temperature will likely continue to rise during the second decade of the 21st century at a rate of $0.12^{\circ} \mathrm{C}$ per decade, which is twice the average rate of $0.52^{\circ} \mathrm{C}$ per century for the past 150 years. This corresponds to a rise in global temperature by $0.6^{\circ} \mathrm{C}-0.7^{\circ} \mathrm{C}$ above the 20th-century mean. Moreover, the DSC model's performance advantage over selected models of other authors suggests that DSC models, when coupled with other eco-environmental models, can be used as a supplemental tool in short-term $(\sim 10$-year $)$ environmental planning and decision making.

Acknowledgements. This research was supported by the Ministry of Science and Technology of China (Grant No. 2010DFB10030) and National Basic Research Program of China (Grant No. 2010CB951504). The authors acknowledge support from the Flemish Interuniversity Council (Grant No. VLIR-UOS NBTP2011-67885) and the Ghent University Laboratory of Soil Science for the writing of this paper.

\section{REFERENCES}

Akaike, H., 1974: A new look at the statistical model identification. IEEE Transactions on Automatic Control, 19, 716-723.
Allen, M. R., and Coauthors, 2006: Quantifying anthropogenic influence on recent near-surface temperature change. Surveys in Geophysics, 27, 491-544.

Bechini, L., S. Bocchi, T. Maggiore, and R. Confalonieri, 2006: Parameterization of a crop growth and development simulation model at sub-model components level. An example for winter wheat (Triticum aestivum L.). Environmental Modelling and Software, 21, 1042-1054.

Bindraban, P. S., and Coauthors, 2012: Assessing the impact of soil degradation on food production. Current Opinion in Environmental Sustainability, 4, 478-488.

Bloomfield, P., 2000: Fourier Analysis of Time Series: An Introduction. 2nd ed., John Willey, 288pp.

Bond-Lamberty, B., and A. Thomson, 2010: Temperatureassociated increases in the global soil respiration record. Nature, 464, 579-582.

Box, G. E. P., G. M. Jenkins, and G. C. Reinsel, 1994: Time Series Analysis: Forecasting and Control. 3rd ed., Prentice-Hall, 592pp.

Caldiz, D. O., F. J. Gaspari, A. J. Haverkort, and P. C. Struik, 2001: Agro-ecological zoning and potential yield of single or double cropping of potato in Argentina. Agricultural and Forest Meteorology, 109, $311-320$

Chapin III, F. S., J. McFarland, A. D. McGuire, E. S. Euskirchen, R. W. Ruess, and K. Kielland, 2009: The changing global carbon cycle: Linking plant-soil carbon dynamics to global consequences. Journal of Ecology, 97, 840-850.

Chung, J.-Y., Y. Honda, Y.-C. Hong, X.-C. Pan, Y.-L. Guo, and H. Kim, 2009: Ambient temperature and mortality: An international study in four capital cities of East Asia. Science of the Total Environment, 408, 390-396.

Conant, R. T., J. M. Klopatek, and C. C. Klopatek, 2000: Environmental factors controlling soil respiration in three semiarid ecosystems. Soil Science Society of America Journal, 64, 383-390.

Dale, V. H., and M. R. English, 1999: Tools to Aid Environmental Decision Making. Springer-Verlag, 342pp.

de Gooijer, J. G., and R. J. Hyndman, 2006: 25 years of time series forecasting. International Journal of Forecasting, 22, 443-473.

Gorden, A. H., 1991: Global warming as a manifestation of random walk. J. Climate, 4, 589-597.

Grace, J., 2004: Understanding and managing the global carbon cycle. Journal of Ecology, 92, 189-202.

Hansen, J., M. Sato, R. Ruedy, K. Lo, D. W. Lea, and M. Medina-Elizade, 2006: Global temperature change. Proc. National Academy of Sciences USA, 103, 14288-14293.

IPCC, 2001: Detection of climate change and attribution of causes. Climate Change 2001: The Scientific Basis. Contribution of Working Group I to the Third Assessment Report of the Intergovernmental Panel on Climate Change, J. T. Houghton et al., Eds., Cambridge University Press, 44pp.

IPCC, 2007: Technical summary. Climate Change 200\%: 
The Physical Science Basis. Contribution of Working Group I to the Fourth Assessment Report of the Intergovernmental Panel on Climate Change, S. Solomon et al., Eds., Cambridge University Press, Cambridge, 74pp.

Jones, P. D., and A. Moberg, 2003: Hemispheric and large-scale surface air temperature variations: An extensive revision and an update to 2001. J. Climate, 16, 206-223.

Jones, P. D., M. New, D. E. Parker, S. Martin, and I. G. Rigor, 1999: Surface air temperature and its changes over the past 150 years. Rev. Geophys., 37, 173-199.

Kerr, R. A., 2009: What happened to global warming? Scientists say just wait a bit. Science, 326, 28-29.

Knight, J., and Coauthors, 2009: Do global temperature trends over the last decade falsify climate predictions? Bull. Amer. Meteor. Soc., 90, S22-S23.

Lean, J. L., and D. H. Rind, 2008: How natural and anthropogenic influences alter global and regional surface temperatures: 1889 to 2006. Geophys. Res. Lett., 35, L18701, doi: 10.1029/2008GL034864.

Lean, J. L., and D. H. Rind, 2009: How will earth's surface temperature change in future decades. Geophys. Res. Lett., 36, L15708, doi: 10.1029/2009GL038932.

Lee, J.-H., and K.-T. Sohn, 2007: Prediction of monthly mean surface air temperature in a region of China. Adv. Atmos. Sci., 24, 503-508, doi: 10.1007/s00376007-0503-1.

Ljung, G. M., and G. E. P. Box, 1978: On a measure of lack of fit in time series models. Biometrika, $\mathbf{6 5}$, 553-564.

Madsen, B. C., T. Kheoh, C. R. Hinkle, and T. Dreschel, 1992: Precipitation chemistry in east Central Florida from 1978 to 1987. Water, Air and Soil Pollution, 65, $7-21$.

Mayhew, P. J., G. B. Jenkins, and T. B. Benton, 2008: A long-term association between global temperature and biodiversity, origination and extinction in the fossil record. Procedings of the Royal Society B, 275, $47-53$.

NCDC (National Climate Data Center), cited 2012: Global surface temperature anomalies. [Available online at: http://www.ncdc.noaa.gov/cmbfaq/anomalies.html.]

Nickerson, D. M., and B. C. Madsen, 2005: Nonlinear regression and ARIMA models for precipitation chemistry in East Central Florida from 1978 to 1997. Environmental Pollution, 135, 371-379.

Peñuelas, J., T. Rutishauser, and I. Filella, 2009: Phenology feedbacks on climate change. Science, 324, 887-888.

R Development Core Team, cited 2008: R: A Language and Environment for Statistical Computing. R Foundation for Statistical Computing, Vienna, Austria. [Available online at http://www.R-project.org.]
Rahmstorf, S., A. Cazenave, J. A. Church, J. E. Hansen, R. F. Keeling, D. E. Parker, and R. C. J. Somerville, 2007: Recent climate observations compared to projections. Science, 316, doi: 10.1126/science.1136843.

Romilly, P., 2005: Time series modeling of global mean temperature for managerial decision-making. Journal of Environmental Management, 76, 61-70.

Schwarz, G. E., 1978: Estimating the dimension of a model. Annals of Statistics, 6, 461-464.

Shumway, R. H., and D. S. Stoffer, 2006: Time Series Analysis and Its Applications with $R$ Examples. 2nd ed. Springer, 575pp.

Smith, T. M., and R. W. Reynolds, 2005: A global merged land-air-sea surface temperature reconstruction based on historical observations (1880-1997). J. Climate, 18, 2021-2036.

Smith, T. M., R. W. Reynolds, T. C. Peterson, and J. Lawrimore, 2008: Improvements to NOAA's Historical Merged Land-Ocean Surface Temperature Analysis (1880-2006). J. Climate, 21, 2283-2296.

Steltzer, H., and E. Post, 2009: Seasons and life cycles. Science, 324, 886-887.

Venables, W. N., and B. D. Ripley, 2002: Modern Applied Statistics with $S$. 4th ed. Springer, 495pp.

Verdoodt, A., E. Van Ranst, and L. Ye, 2004: Daily simulation of potential dry matter production of annual field crops in tropical environments. Agronomy Journal, 96, 1739-1753.

Visser, H., and J. Molenaar, 1995: Trend estimation and regression analysis in climatological time series: an application of structural time series models and the random filter. J. Climate, 8, 969-979.

Wang, S., Q. Ge, F. Wang, X. Wen, and J. Huang, 2010a: Key issues on debating about the global Warming. Advances in Earth Science, 25, 656-665. (in Chinese)

Wang, S., Y. Luo, G. Tang, Z. Zhao, J. Huang, and $\mathrm{X}$. Wen, 2010b: Does the global warming pause in the last decade: 1999-2008? Advances in Climate Change Research, 6, 95-99. (in Chinese)

Ye, L., and E. Van Ranst, 2002: Population carrying capacity and sustainable agricultural use of land resources in Caoxian County (North China). Journal of Sustainable Agriculture, 19, 75-94.

Ye, L., and E. Van Ranst, 2009: Production scenarios and the effect of soil degradation on long-term food security in China. Global Environmental Change, 19, $464-481$.

Ye, L., H. Tang, J. Zhu, A. Verdoodt, and E. Van Ranst, 2008: Spatial patterns and effects of soil organic carbon on grain productivity assessment in China. Soil Use and Management, 24, 80-91.

Ye, L., and Coauthors, 2012: Climate change impact on China food security in 2050. Agronomy for Sustainable Development, doi: 10.1007/s13593-012-0102-0. 